\title{
Synthesis and Antibacterial Activity of Some New Azo Disperse Dyes Containing Selenium and Their Application In Polyester Printing
}

\author{
Elkhabiry Shaban $^{1}$, S. H. Nassar ${ }^{1}$, Saad Shabban ${ }^{2}$, Hatem E.Gaffer ${ }^{1 *}$ \\ ${ }^{1}$ Dyeing, Printing and Textile Auxiliaries Department, Textile Research Division, \\ National Research Centre, 33 El-Bohouth Street, Dokki, Giza 12622, Egypt. \\ ${ }^{2}$ Department of Chemistry, Faculty of Science, Mansoura University, Egypt.
}

\begin{abstract}
TN THIS study the synthesis of novel azo dyes containing selenium was designed and synthesized with high yields from simple aniline selenocyanate $\mathbf{1}$ which coupled with some diazotized aromatic amines to give new azo dye. The novel synthesized selenium dyes were utilized for silk screen printed polyester fabrics. Color strength and fastness properties were measured and exhibited high efficiency for washing, perspiration, rubbing, and light fastness. Moreover, the new dyes were tested for antibacterial activity.
\end{abstract}

Keywords: Selenocyanate, Azo coupling, Antibacterial activity (in vitro).

\section{Introduction}

Azo chromophores dye based on heterocyclic system has witnessed large invention in recent years [1]. Due to their excellent properties homocyclic azo dyes are an essential class for polyester fabric and also in non-textile application, such as medicine, photodynamic therapy, laser, and non-linear optical systems [2]. Moreover, organoselenium structures are commonly used as intermediates in the dyestuff, organoselenium are important substrates for the synthesis and modification of many fused hetero ring systems, which play an important role in biomedical and biological activities [3]. Many symmetrical diselenide dyes were synthesized and applied on polyester fabrics with good fastness properties [4]. Mount epidemiological studies have related the disorder in selenium-body status with the increased risk of many cancers, including breast cancer [5]. Since there is a great similarity of the chemical properties between sulfur and selenium, in comparison selenium heterocyclic compounds have more biological importance [6-10].

On the other hand, organo-selenium compounds known to exhibit prominent sensitizing processes in living organisms, and the selenium atom displays powerful constituent of four proteins. Thus, the shortage of the selenium concentration in the human body is the main reason for dangerous chronic diseases such as necrosis of the liver [11].

The current study describes the synthesis and evaluates the cytotoxic activity of novel azo disperse dyes containing selenium by reacting amino selenocyanate with phenacyl bromide and couplings with diazotized aniline derivatives. We also inspected whether selenocyanate groups located on the spacer of the azo dye moiety, increase the affinity and efficiency for silk screen printed Polyester fabric with acceptable and good fastness properties as well as enhancement of its biological activity which could be used in various fields of life applications.

\section{$\underline{\text { Results and Discussion }}$}

The Synthesis of novel azo disperses dyes containing organoselenium moiety was prepared with high yields. Therefore, simple and new approaches for the synthesis of novel azo dye containing selenium by using more stable and less toxic compounds and easily accessible methods are also required.

Compound $\mathbf{1}$ is considered as bifunctionalized structure contains two active cites, free amino and selenocyanate groups. Under basic conditions, compound $\mathbf{1}$ reacts only as a

*Corresponding author e-mail: hatem197@yahoo.com 
primary aromatic amine with phenacyl bromide since the selenocyante group is quite unreactive under these conditions, then followed by coupling with substituted diazotized aniline as shown in Scheme 1.

The main objective of this work is concerning with the studying of the printing properties of the prepared new azo dyes bearing selenium moiety. It was found that azo dye containing selenium analogues $\mathbf{3 a}, \mathbf{3 b}, \mathbf{3} \mathbf{c}$ and 3d have higher cytotoxic effect. The presence of cynoselenium system enhances and increases the antimicrobial activity of the prepared dyes.

\section{Fastness properties}

The colour characteristics of printed polyester fabric samples were investigated and are given in Table 1. The data in the table indicate that the colour strength of the printed polyester fabric (which expressed as K/S) depended upon the difference in the nature of varied substituent's attached to arylazo moity of the synthesized dye molecules used., for ex dye no. 3c possess colour strength higher than their corresponding samples printed have electron-donating group and this may be higher conjugation attributed to presence of electron withdrawing groups $\left(\mathrm{Cl}, \mathrm{NO}_{2}\right)$. The printed polyester samples using the prepared dyes $3 \mathrm{a}-\mathrm{d}$ were thermo fixed at temperatures $180{ }^{\circ} \mathrm{C}$ five minutes. The fixation temperature plays an important role in facilitates the mobility of the dye molecules and increases the rate of its transfer from the printed film into the fabric.

\section{Washing fastness}

The wash fastness of the printed polyester fabric with dyes 3a-d was exhibit a good to very good results in both alteration and staining on cotton. The good washing fastness result is due to the high stability of the dye molecules on the polyester fabric. Compound $3 \mathrm{c}$ and $3 \mathrm{~d}$ showing excellent wash fastness due to the terminal electron withdrawing group as summarized in Table 1.

\section{Perspiration fastness}

The amount of the synthesized dyes removed from polyester fabric under the effect of perspiration solution (alkali and acidic) are given in Table 1. The results of all the printed samples<smiles>N#Cc1ccc(N)c2ccccc12</smiles>

1

\section{$\mathrm{PhCOCH}_{2} \mathrm{Br}$}

Acetone, $\mathrm{K}_{2} \mathrm{CO}_{3}$ $50{ }^{\circ} \mathrm{C}$<smiles>N#Cc1ccc(NCC(=O)c2ccccc2)c2ccccc12</smiles>

2

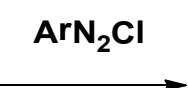<smiles>[R]c1ccc(/N=N/C(Nc2ccc(S(=O)(=O)c3ccccc3)c3ccccc23)C(=O)c2ccccc2)cc1</smiles>

3a-d

$\mathrm{R}:=\mathrm{H}, \mathrm{CH}_{3}, \mathrm{NO}_{2}, \mathrm{Cl}$

Scheme 1. Azo coupling of active methylene aniline selenocyanate.

TABLE 1. K/S and fastness properties of the printed polyester fabric using dyes 3a-d.

\begin{tabular}{|c|c|c|c|c|c|c|c|c|c|c|}
\hline \multirow{3}{*}{ Sample } & \multirow{3}{*}{$\mathbf{K} / \mathbf{S}$} & \multirow{3}{*}{$\begin{array}{c}\text { Light } \\
\text { fastness }\end{array}$} & \multirow{2}{*}{\multicolumn{2}{|c|}{$\begin{array}{l}\text { Washing } \\
\left.\text { fastness }^{a}\right)\end{array}$}} & \multirow{2}{*}{\multicolumn{2}{|c|}{ Rubbing }} & \multicolumn{4}{|c|}{ Perspiration fastness ${ }^{a)}$} \\
\hline & & & & & & & \multicolumn{2}{|c|}{ Acidic } & \multicolumn{2}{|c|}{ Alkaline } \\
\hline & & & St. & Alt & Wet & Dry & St. & Alt & St. & Alt. \\
\hline $3 a$ & 5.54 & 6 & $3-4$ & 4 & $3-4$ & 4 & 4 & 4 & $4-5$ & 4 \\
\hline $3 b$ & 5.77 & 6 & 4 & $3-4$ & $3-4$ & 4 & $3-4$ & 4 & 4 & $4-5$ \\
\hline $3 c$ & 7.73 & 7 & $4-5$ & $4-5$ & $4-5$ & $4-5$ & $4-5$ & $4-5$ & $4-5$ & $4-5$ \\
\hline $3 d$ & 5.86 & 7 & $4-5$ & $4-5$ & 4 & $4-5$ & $4-5$ & $4-5$ & $4-5$ & $4-5$ \\
\hline
\end{tabular}

Egypt.J.Chem. Special Issue (2017) 
are showing good to very good perspiration fastness. As expected the electron withdrawing group effect in the stability of dye molecules in the printed fabric was higher than the dye derivative which is not bearing these groups as shown in Table 1.

\section{Rubbing fastness}

The rubbing fastness of the printed polyester samples exhibit good fastness properties, this is a results of good fixation of the dye on the fiber as well as the efficiency of binding force. The obtained results demonstrate that the higher values of rubbing fastness are for dyes with the higher molecular weights. Thus, dyes $3 \mathrm{c}$ give very good rubbing fastness results.

\section{Light fastness}

The printed polyester fabrics with the prepared dyes 3a-d showing excellent light fastness as mentioned in Table 1. Dyes 3c- $d$ shows higher fastness due to the presence of nitro group (3c) as well as the effect of terminal chlorine atom in dye (3d).

\section{Antimicrobial activity}

Antimicrobial activity

In our hands now we found that the printed goods of Selenide dyes were treatment evaluated against different type of antimicrobial such as gram positive (Staphylococcus aureus) and gram negative (Escherichia coli) bacterial pathogens as well as Candida albicans fungus (yeast) strain. Antimicrobial evaluation were done by the agar well diffusion method using $100 \mu \mathrm{L}$ of suspension containing $1 \times 108 \mathrm{CFU} / \mathrm{mL}$ of tested pathological bacteria and $1 \times 104$ spores $/ \mathrm{mL}$ of fungi spread on nutrient agar (NA), and potato dextrose agar (PDA) medium respectively. After the media had cooled and solidified, paper discs of $6 \mathrm{~mm}$ diameter soaked with $20 \mu \mathrm{l}$ of the test compounds $(1 \mathrm{mg} / \mathrm{ml})$ were added to the agar plates and incubated at 30 ${ }^{\circ} \mathrm{C}$. After incubation time, antimicrobial activity was evaluated by measuring the zone of inhibition against the test organisms and compared with that of the standard.

\section{Conclusion}

New series of novel azo dyes containing selenium was designed, synthesized and elucidated by elemental analysis, FTIR, ${ }^{1} \mathrm{H}$ NMR and mass spectroscopic tools. The novel synthesized selenium-containing dyes were applied for silk screen printing on polyester fabrics. Color measurements and fastness properties of the prepared dyes exhibited a high efficiency for washing, perspiration, rubbing, and

TABLE 2. Diameters (in $\mathrm{mm}$ ) of inhibition zones of agar diffusion assays against a variety of fungi and bacteria (growth was quantified after 2 days). ${ }^{a}$

Compd. No.

Diameter inhibition zone in $\mathrm{mm}(\%$ activity index $)$

\begin{tabular}{cccc} 
& E. coli & S. aureus & C. albicans \\
\hline 3a & $14(62)$ & $13(54)$ & $19(74)$ \\
3b & $11(67)$ & $17(62)$ & $11(39)$ \\
3c & $31(100)$ & $24(100)$ & $13(35)$ \\
3d & $19(58)$ & $13(52)$ & $22(100)$ \\
Tetracycline TC & 32 & 35 & 00 \\
\hline
\end{tabular}

a Diameters (mm) of zones of inhibition (agar diffusion assay) are provided. In each case, $6 \mathrm{~mm}$ disks with $20 \mu \mathrm{g}$ of the test compounds were incubated. penicillin and strptomycine were used as the positive control.

light fastness. The satisfactory performance and good antibacterial properties of the synthesized dyes should lead to design of novel antibacterial disperse dyes with increasing the efficacy of application properties.

\footnotetext{
Materials

Fabrics

Polyester $(150 \mathrm{~g} / \mathrm{m} 2)$. supplied by Egyptian
}

and developing Co., Cairo, Egypt.

\section{Thickening agents}

Daico Thic 1600, synthetic thickener for azo disperse silk screen printing was kindly supplied by Daico company.

$$
\begin{aligned}
& \text { Dye stuffs } \\
& \text { 3a, 3b, 3c, and 3d }
\end{aligned}
$$


Chemicals

- Sodium dihydrogen phosphate, sodium chloride, all of laboratory grade, were used.

\section{Fastness testing}

The printed samples were subjected to rubbing, washing, perspiration and light according to standard ISO methods, ISO 105-X12 (1987), ISO 105-co4 (1989), ISO105-EO4 (1989), ISO 105-BO2 (1988) respectively.

\section{Experimental}

The progress of all reactions was monitored using thin layer chromatography (TLC) analysis obtained from Merck with a $0.2 \mathrm{~mm}$ thick TLC plates (aluminium-backed, silica gel 60 F245) and spots were located by UV light. All ${ }^{1} \mathrm{HNMR}$ experiments were carried out with a $300 \mathrm{MHz}$ Bruker Avance DRX-400 spectrometer at Cairo University, Egypt Deuterated chloroform and dimethyl sulfoxide (chloroform-d, $\mathrm{CDCl}_{3}$ and DMSO-d6) were used as solvents in all routine NMR measurements. Chemical shifts are reported in ppm relative to the respective deuterated solvent peak $\mathrm{CDCl}_{3}(\delta 7.27$ ppm), DMSO-d6 ( $\delta 2.50 \mathrm{ppm})$ for ${ }^{1} \mathrm{H}$ and $\mathrm{CDCl}_{3}$ ( $\delta 77$ ppm), DMSO-d6 ( $\delta 39.51$ ppm) coupling constants in $\mathrm{Hz}$.

The elemental analysis and the microanalysis were performed in microanalysis laboratory at Cairo University. HRMS Accurate mass measurements were measured using either Thermo Finnigan MAT95XP or Thermo Scientific LTQ Orbitrap XL mass spectrometers. The determinations of Melting point were carried out using Stuart Scientific SMP1 apparatus. All the solvents were of analytic grade and used directly without any purification.

\section{Textile printing \\ Preparation of printing paste \\ - The printing paste was prepared according to the following recipe:}

\section{Printing technique}

The conventional silk screen printing

\begin{tabular}{lc} 
Dye & $40 \mathrm{~g}$ \\
Thickener & $2-5 \mathrm{~g}$ \\
Lyprint & $3 \mathrm{~g}$ \\
Sodium dihydrogen phosphate & $5 \mathrm{~g}$ \\
Sodium chloride & $10 \mathrm{~g}$ \\
Water & $\mathrm{x}$ \\
\cline { 2 - 2 } & 1000
\end{tabular}

technique was used.

Fixation

Fixation was done by thermofixation of the printed fabrics at $180^{\circ} \mathrm{C}$ for 5 minutes using an automatic oven (Wener Mathics Co., Switzerland).

Reduction clear and washing

Washing of the printed fabrics was carried out as follows:

- Rinsing in cold water.

- Soaping at $60{ }^{\circ} \mathrm{C}$ with $2 \mathrm{~g} / \mathrm{L}$ Hostapal CV ( non ionic detergent) for 20 minutes.

Reduction clear with $2 \mathrm{~g} / \mathrm{L}$ hydrosulphite, $2 \mathrm{~g} / \mathrm{L}$ sodium hydroxide ( $32.5 \%$ ), 2g/L Hostapal $\mathrm{CV}$ ( non ionic detergent) at $40-70^{\circ} \mathrm{C}$.

- Rinsing at $60-70{ }^{\circ} \mathrm{C}$

- Cold rinsing.

\section{Colour measurements}

The color yield of the printed samples was evaluated by light reflectance technique using the Perkin-Elmer, UV/V Spectrophotometer (Model, Lambda 3B). The color strength (K/S value) was assessed using Kubelka-Munk equation.

$$
\boldsymbol{K} / \boldsymbol{S}=\frac{(1-\boldsymbol{R})^{2}}{2 \boldsymbol{R}}
$$

Where,

$\mathrm{R}=$ decimal fraction of the reflection of the dyed fabric,

$\mathrm{K}=$ absorption coefficient, and $\mathrm{S}=$ scattering coefficient

Synthesis

Synthesis of 4-selenocyanatonaphthalen-1amine (1) [12]

To a well stirred solution of malononitrile (0. $2 \mathrm{~g}, 3 \mathrm{mmol})$ in DMSO $(2 \mathrm{~mL}), \mathrm{SeO}_{2}(0.67$ $\mathrm{gm}, 6 \mathrm{mmol})$ was added. The mixture became reddish after $10 \mathrm{~min}$ and an exothermic reaction with vigorous gas evolution began during the next $5 \mathrm{~min}$. When the gas evolution was ceased the reaction mixture was filtered to remove any solids present, then napthyl amine $(0.64 \mathrm{~g}, 4.5$ mmol) was added with stirring. Stirring was continued for additional $1 \mathrm{~h}$ at room temperature. The homogenous solution was diluted with icecold water, the precipitate formed was filtered off, air dried and recrystallized from ethanol to give $\mathbf{1}$.

Synthesis of 1-phenyl-2-((4-selenocyanatonaphthalen-1-yl) amino)ethanone (2) 
To a solution of 4-selenocyanatonaphthalen-1amine (1) (0.25 g, $1.00 \mathrm{mmol})$ in dry Acetone (15 $\mathrm{ml}$ ) containing $\mathrm{K}_{2} \mathrm{CO}_{3}(2 \mathrm{~g})$, Phenacyl bromide ( 0.2 $\mathrm{g}, 1.00 \mathrm{mmol})$ was added dropwise with stirring at $50{ }^{\circ} \mathrm{C}$. Stirring was continued for $4 \mathrm{~h}$ at room temperature and the reaction mixture was poured into ice cooled water. The resulting precipitate was collected, dried and recrystallized from ethanol.

Synthesis of 1-phenyl-2-(phenyldiazenyl)-2-((4selenocyanatonaphthalen-1-yl)amino)ethanone $(3 a-d)$

A solution of sodium nitrite $(0.70 \mathrm{~g}$ in $10 \mathrm{ml}$ water) was gradually added to a well-cooled (0-5 $\left.{ }^{\circ} \mathrm{C}\right)$ solution of different aromatic amines (10.0 mmol) in concentrated $\mathrm{HCl}(3.0 \mathrm{ml})$. The diazonium salt solutions was added with continuous stirring to a cold $\left(0-5^{\circ} \mathrm{C}\right)$ solution of the active methylene compound of 4-selenocyanatonaphthalen-1-amine $2(10.0 \mathrm{mmol})$ in ethanol $(50.0 \mathrm{ml})$ and sodium acetate $(4.0 \mathrm{~g})$. The reaction mixture was allowed to stir at $\left(0-5{ }^{\circ} \mathrm{C}\right)$ for 2 hours, and then the solid was collected by filtration. The obtained precipitate was dried and recrystallized from ethanol.

1-phenyl-2-(phenyldiazenyl)-2-(4-selenocyanatonaphthalen-1-yl)amino)ethanone (3a)

M.p. $196^{\circ} \mathrm{C}$, yield $(79 \%)$. IR (KBr): v/cm ${ }^{-1}$ $=3442(\mathrm{~N}-\mathrm{H}), 2923(\mathrm{C}-\mathrm{H}), 2226(\mathrm{CN}), 1701$ $(\mathrm{C}=\mathrm{O}), 1263$ (C-N), 540 (Se-C); ${ }^{1} \mathrm{H}$ NMR (300 MHz, DMSO-d6) $\delta 1.72(\mathrm{~s}, 1 \mathrm{H}, \mathrm{CH}), 7.32(6 \mathrm{H}$, m, H-Ar), 7.45 (5H, m, H-Ar), $7.76(5 \mathrm{H}, \mathrm{m}$, H-Ar), 11.77 (1H, br, NH); EIMS m/z (\%) 470.06 $(\mathrm{M}+, 323,2)$; Anal. Calcd. For $\mathrm{C}_{25} \mathrm{H}_{18} \mathrm{~N}_{4} \mathrm{OSe}$ (469.40); C, 63.97; H, 3.67; N, 11.94, Found: C, 63.82; H, 3.63; N, 11.73 .

1-phenyl-2-(4-selenocyanatonaphthalen-1-yl) amino)-2-(p-tolyldiazenyl)ethanone (3b)

M.p. $187^{\circ} \mathrm{C}$, yield $(86 \%)$. IR (KBr): v/ $\mathrm{cm}^{-1}=$ 3447(N-H), 2935C-H), $2221(\mathrm{CN}), 1709(\mathrm{C}=\mathrm{O})$, 1266 (C-N), 544 (Se-C) ${ }^{1} \mathrm{H}$ NMR (300 MHz, DMSO-d6) $\delta 0.93\left(\mathrm{~s}, 3 \mathrm{H}, \mathrm{CH}_{3}\right), 1.76(\mathrm{~s}, 1 \mathrm{H}, \mathrm{CH})$, 7.47 (6H, m, H-Ar), $7.56(5 \mathrm{H}, \mathrm{m}, \mathrm{H}-\mathrm{Ar}), 7.62(2 \mathrm{H}$, d, H-Ar), 7.65 (2H, d, H-Ar), 11.67 (1H, br, NH) ; EIMS m/z (\%) 484.08 (M+, 346,98); Anal. Calcd. For $\mathrm{C}_{26} \mathrm{H}_{20} \mathrm{~N}_{4}$ OSe (483.42); C, 64.60; H, 4.17; N, 11.59, Found: C, 64.47; H, 4.08; N, 11.38.

2-((4-nitrophenyl)diazenyl)-1-phenyl-2-((4selenocyanatonaphthalen-1-yl)amino)ethanone (3c)

M.p. $218^{\circ} \mathrm{C}$, yield $(76 \%)$. IR (KBr): v/ $\mathrm{cm}^{-1}=$ 3452(N-H), 2944C-H), $2225(\mathrm{CN}), 1711(\mathrm{C}=\mathrm{O})$, 1268 (C-N), 547 (Se-C); ${ }^{1} \mathrm{H}$ NMR (300 MHz, DMSO-d6) $\delta 1.24(\mathrm{~s}, 1 \mathrm{H}, \mathrm{CH}), 7.16(6 \mathrm{H}, \mathrm{m}$,
H-Ar), 7.38 (5H, m, H-Ar), 7.71 (2H, d, H-Ar), $7.76(2 \mathrm{H}, \mathrm{d}, \mathrm{H}-\mathrm{Ar}), 11.24(1 \mathrm{H}, \mathrm{br}, \mathrm{NH})$; EIMS m/z (\%)514.39 (M+, 162,16); Anal. Calcd. For $\mathrm{C}_{25} \mathrm{H}_{17} \mathrm{~N}_{5} \mathrm{O}_{3} \mathrm{Se}$ (514.39); C, 58.37; H, 3.33; N, 13.61, Found: C, 58.19; H, 3.21; N, 13.46.

2-((4-chlorophenyl)diazenyl)-1-phenyl-2-((4selenocyanatonaphthalen-1-yl)amino)ethanone (3d)

M.p. $197^{\circ} \mathrm{C}$, yield $(80 \%)$. IR $(\mathrm{KBr}): \mathrm{v} / \mathrm{cm}^{-1}=$ 3398(N-H), 2907C-H), $2224(\mathrm{CN}), 1712(\mathrm{C}=\mathrm{O})$, 1246(C-N), 544 (Se-C); ${ }^{1} \mathrm{H}$ NMR (300 MHz, DMSO-d6) $\delta 1.76(\mathrm{~s}, 1 \mathrm{H}, \mathrm{CH}), 7.47(6 \mathrm{H}, \mathrm{m}$, H-Ar), 7.56 (5H, m, H-Ar), 7.63 (2H, d, H-Ar), $7.68(2 \mathrm{H}, \mathrm{d}, \mathrm{H}-\mathrm{Ar}), 11.67(1 \mathrm{H}, \mathrm{br}, \mathrm{NH})$; EIMS $\mathrm{m} / \mathrm{z}(\%) 503$ (M+, 258.13); Anal. Calcd. For $\mathrm{C}_{25} \mathrm{H}_{17} \mathrm{ClN}_{4} \mathrm{OSe}$ (503.84); C, 59.60; H, 3.40; N, 11.12, Found: C, 59.43; H, 3.37; N, 11.06.

\section{Funding}

This research received no specific grant from any funding agency in the public, commercial, or not-for-profit sectors.

\section{Acknowledgment}

Authors would like to thank Micro Analytical Unit, Faculty of Science, Mansoura University, Cairo, Egypt for their excellent technical assistance during the antimicrobial evaluation of the synthetic dyes.

\section{References}

1. Choi J. H., Hong S. H., Lee E. J. and Towns A. D., Structure-wet fastness relationships of some blue disperse dyes for polyester. J. Soc. Dyers Colour, 116, 278 (2000).

2. Fox S., Moussalli D.M., Johnston A. and Owens G.R., Evolution of color variation in dragon lizards: quantitative tests of the role of crypsis and local adaptation. Evolution, 58, 1549 (2004).

3. Shaaban S., Arafat M.A., Gaffer H. E. and Hamama W. S., Synthesis and anti-tumor evaluation of novel organoselenocyanates and symmetrical diselenides dyestuffs. Der Pharma Chemica, 6,186 (2014).

4. Gaffer H.E., Shaaban S., Abbas N. and Abdel-latif E., Synthesis of some new symmetrical diselenide dyestuffs for dyeing polyester fabrics. Pig. \& Resin Technology, 45, 438 (2016).

5. Shaaban S., Gaffer H.E., Jabar Y. and Elmorsy S. S., Cytotoxic naphthalene based - symmetrical diselenides with incresded selectivity against MCF7 breast cancer cells. Int J Pharm; 5, 73 (2015).

6. Mugesh G., du Mont W.W. and Sies H. Chemistry Egypt.J.Chem. Special Issue (2017) 
of biologically important synthetic organoselenium compounds Chem. Rev, 101, 2125 (2001).

7. Abdel-Hafez S.H. and Hussein M.A., Selenium containing heterocycles: synthesis and pharmacological activities of some new $4 \square$ methylquinoline $\square 2$ (1H) selenone derivatives. Arch. Pharm. (Weinheim), 341, 240 (2008).

8. Padmavathi V., Mahesh K., Nagendra AV.M. and Padmaja A. Synthesis and bioassay of oxazolyl/ thiazolyl selenadiazoles, thiadiazoles and diazaphospholes. Chem. Pharm. Bull(Tokyo), 57, 561 (2009).

9. Garud DR., Koketsu, M. and Ishihara, H. Isoselenocyanates: a powerful tool for the synthesis of selenium-containing heterocycles. Molecules, 12, 504 (2007).

10. Shaabana S., Negm A., Ibrahim E.E. and Elrazak A.A., Hepatocellular carcinoma chemotherapeutic agents: efficacy and mode of action. Onc Rev, 8, 25 (2014).

11. Khalifa M.E., Abdel-Hafez S.H., Gobouri A.A. and Kobeasy M.I., Synthesis and biological activity of novel arylazothiazole disperse dyes containing selenium for dyeing polyester fibers. Phosphorus, Sulfur, and Silicon and the Related Elements, 190, 461 (2015).

12. Kachanov VA., Slabko Y.O., Baranova V.O., Shilova, V.E. and Kaminskii, A.V. Triselenium dicyanide from malononitrile and selenium dioxide. One-pot synthesis of selenocyanates Tetrahedron letters, 45, 4463 (2004).

(Rececived 27/8/2017; accepted 5/12/2017)

$$
\begin{aligned}
& \text { تثييد بعض الاصباغ المنتشره الجديده ذات نشاط قاتل للبكتريا و المحتويه على السيلنيوم }
\end{aligned}
$$

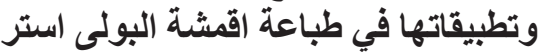

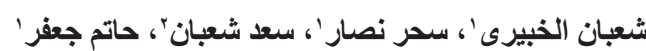

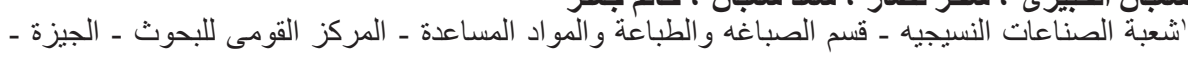

$$
\begin{aligned}
& \text { "قصم الكيمياء- كلية العلوم - جامعة المنصورة - مصر. }
\end{aligned}
$$

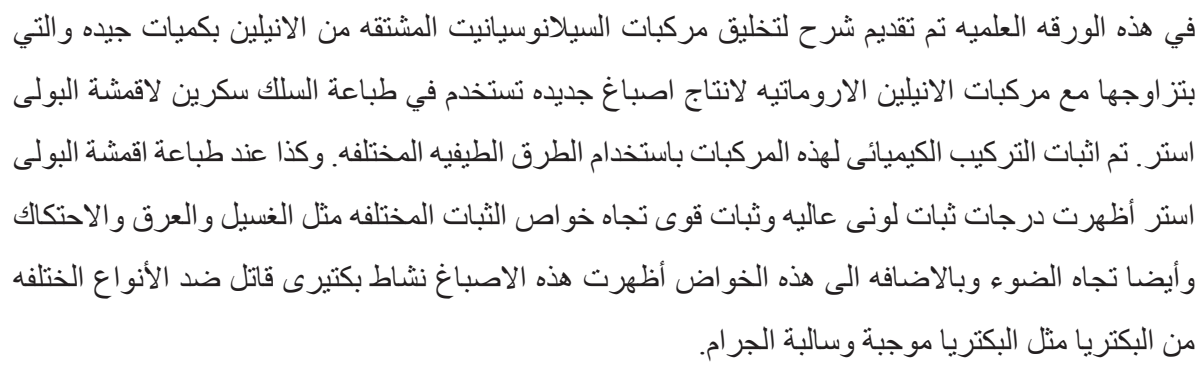

